\title{
2018 Dünya Kupasında Müsabakaları Kazanan ve Kaybeden Takımların Bazı
}

\section{Performans Parametrelerinin Karşılaştırılması}

\author{
Oğuz GÜRKAN ${ }^{1 *}$ (D) Bekir Barış CiHAN ${ }^{1}$ Mehmet YILDIRIM ${ }^{1}$ \\ Hayrettin GÜMÜŞDAĞ ${ }^{1}[$
}

${ }^{1}$ Yozgat Bozok Üniversitesi, Beden Eğitimi ve Spor Yüksekokulu, YOZGAT

DOI: 10.31680/gaunjss.567109

Orijinal Makale / Original Article

Geliş Tarihi / Received: 17.05.2019
Kabul Tarihi / Accepted: 16.10.2019

\section{Öz}

Bu çalışma 2018 Dünya Kupasında müsabakaları kazanan ve kaybeden takımların bazı performans parametrelerini karşılaştırmak amacıyla yapılmıştır. Turnuvaya 32 takım katılmış olup, turnuvada toplam 64 müsabaka oynanmıştır. Müsabakaların verileri FiFA'nın (Uluslararası Futbol Federasyonları Birliği) resmi web sayfasından elde edilmiştir. Elde edilen verilerin istatistiksel analizi için SPSS 22 Paket programı kullanılmıştır. Verilerin normal dağılıma uygun olup olmadığını tespit etmek için Shapiro Wilk testi uygulanmış ve verilerin normal dağılıma uygun olduğu gözlemlenmiştir. Bunun sonucunda da bağımsız gruplarda parametrik testlerden İndependent Samples $t$ testi uygulanmıştır. Veriler ortalama ve standart sapma olarak verilmiş ve $p<0.05$ istatistiksel olarak anlamlı kabul edilmiştir. Elde edilen sonuçlara göre, iki grup arasında atılan gol, hedefi bulan şut ve sarı kart açısından istatistiksel olarak bir farklılık bulunmuş iken $(p<0.05)$, iki grup arasında kat edilen toplam mesafe, pas, olumlu pas, topa sahip olma, şut, korner, ofsayt, top kazanma ve faul parametreleri açısından istatistiksel olarak anlamlı bir farklılık tespit edilememiştir $(p>0.05)$. Sonuç olarak, müsabakalardan galip ve mağlup ayrılan takımların belirtilen parametrelerde birbirine yakın ortalamalara sahip olduğu, fakat galip takımların şut ve olumlu şut ortalamalarının daha yüksek olduğu gözlemlenmiştir. Müsabakalarda daha fazla şut atan takımların maçlardan galip ayrılma durumlarının daha yüksek olduğu söylenebilir. İki grup arasında kat edilen mesafeler açısından da bir farklılığın olmaması, futbolda takımsal açıdan çok fazla mesafe kat etmenin çok önemli olmadığı, kat edilen mesafelerin maç içinde o anki skora, topun hangi takımda olduğuna, oyuncu mevkilerine ve fiziksel eforun alt bileşenlerine göre detaylandırılarak sunulmasının daha çok amaca hizmet edeceği söylenebilir.

Anahtar Kelimler: Futbol, Dünya Kupası, Maç Analizi, İstatistiksel Analiz

\section{Comparing the Some Performance Parameters of the Winning and Losing Teams of World Cup 2018}

\begin{abstract}
The present study was carried out in order to compare some performance parameters of the winning and losing teams of World Cup 2018. The game data were obtained from official webpage of FIFA. SPSS 22 package software was used for the statistical analysis of data obtained. Shapiro Wilk Test was used in determining if the data fit normal distribution, and it was found that the data were distributed normally. Thus, among the parametric tests, the Independent Samples t test was used for the independent groups. According to the results obtained, a statistically significant difference was found between two groups in terms of goals scored, balls shot spotting the target, and yellow card $(p<0.05)$, however no significant difference was found in terms of total distance, positive pass, possession of the ball, offside, shot, corner, winning the ball, and foul parameters $(p>0.05)$. In conclusion, it was determined that the winning teams and losing teams had similar mean values in examined parameters but the winning teams had higher mean scores in terms of shot and positive shot parameters. The fact that there was no significant difference between the groups in terms of total distance travelled suggests that the total distance travelled has no effect on the match result.
\end{abstract}

Keywords: Football, World Cup, Match Analysis, Statistical Analysis

\footnotetext{
* Sorumlu Yazar: Oğuz GÜRKAN
}

E-mail: oguz.gurkan@bozok.edu.tr 


\section{Giriş}

19. yüzyılda İngilizler tarafından geliştirilen futbol oyunu 20. yüzyılda bütün dünyaya yayılarak, en çok ilgi duyulan ve en çok taraftar kitlesine sahip olan popüler bir spor branşıdır (Akgeyik, 2018). Bugün dünya çapında düzenli olarak futbol izleyen insan sayısı milyarlarla ifade edilmektedir. Uluslararası rekabet ortamına sahip olan FIFA ve UEFA gibi organizasyonlar milyarlarca futbol seyircisini televizyon ekranlarına taşımaktadır (İnan, 2018). Futbol Dünya Kupası hiç kuşkusuz dünyadaki en büyük organizasyonlardan birisidir. Dünya kupası bize dünyanın en iyi takımlarını ve oyuncularını karşılaştırma imkanı sunar. Genellikle sonuçlanan bir dünya kupasından sonra başarılı takımların oyun stilleri değerlendirilerek, başarının altında yatan performans parametrelinin analizi yapılır (Hughes ve Franks, 2005). Bu analizleri yapabilmek için de objektif değerlendirme yöntemleri kullanılmaktadır. Futbolda takım analizi ve bir futbolcunun bireysel analizi futbol oyununun hızlı yapısından dolayı subjektif bir değerlendirmeye neden olmaktadır. Bu taraflı değerlendirmeler de antrenörlerin objektif kararlar vermelerini güçlendirmektedir (Müniroğlu, 2009). Bu nedenle maç sırasında doksan dakikalık bir oyunu hafızada tutmak için bazı alternatif yöntemlere başvurulmuştur. Bu yöntemlerden olan kağıt kalem metodu ve bilgisayar-video analiz ile bir futbolcunun tüm davranışları doğru ve objektif bir şekilde incelenmekte ve kaydedilmektedir (Franks ve Hughes, 2016). Maç analizi antrenörlerin kendi takımlarının güçlü ve zayıf yönlerini tespit etmesine olanak sağlayarak, takımlarının gelişimine katkıda bulunmaktadır. Benzer bir şekilde antrenörler maç analizi sayesinde rakip analizi de yaparak, karşılaşacakları rakiplerin güçlü ve zayıf yönlerini tespit edebilmektedirler (Carling ve ark., 2008). Yine Müsabaka analizi birçok spor dalında yaygın bir şekilde kullanılmakta ve antrenörlere performans ile ilgili tarafsız geri bildirimler sunmaktadır (Carling ve ark., 2005). Maç Analizi performans esnasındaki bilgilerin objektif bir şekilde kaydedilmesi ve bu performans sırasındaki dataların istatistiksel sonuçlarla yorumlanması işlemidir (Müniroğlu ve Deliceoğlu, 2008).

Bilgisayar bilimindeki teknolojik ilerlemelerle birlikte, müsabaka sırasında meydana gelen pas, şut, top kazanma, gol gibi parametrelerin analizi yapılabilmekte ve oyunculara bunlarla ilgili geri bildirimler verilebilmektedir (Hughes, 2003). Günümüz futbolunda maç sonucuna etki eden birçok değişken bulunmaktadır. Takımların topa sahip olma yüzdeleri, atmış oldukları şut sayıları, pas parametreleri ve ceza alanına attıkları toplar bu değişkenler arasında gösterilebilir. Sayısal olarak 
bir takımın rakibine karşı üstünlük sağlamasının müsabakayı kazanmak için yeterli olacağı algısına düşülmemesi gerekir. Fakat elde edilen datalar sporcunun gelişimine, takım oyununa ve takımın gelecekteki maçlardan pozitif sonuçlar almasına katkı sağlayacak önemli bir unsurdur (Bakır, 2007). Buna ilaveten bazı parametrelerde rakiplerine karşı sayısal olarak üstünlük kuran takımların, maç sonu skor anlamında da bir üstünlük kurabileceği de söylenilebilir. Literatürü incelediğimizde müsabakalardan galip gelen ve mağlup ayrılan takımlar arasında bazı performans parametreleri açısından farklılıkların olduğu gözlemlenmiştir. UEFA Şampiyonlar Liginde yapılan bir çalışmada, maçları kazanan takımların toplam şut, hedefi bulan şut, pas ve başarılı pas ortalamalarının daha yüksek olduğu ve aynı zamanda istatistiksel olarak anlamlı olduğu sonucuna ulaşılmıştır (Penas ve ark., 2011). 2012-2013 sezonunda İngiltere Premier liginde ilk 10 ve son 10 sıradaki takımların karşılaştırılmasının yapıldığı bir çalışmada, ilk 10 sıradaki takımların orta, şut ve hedefi bulan şut ortalamalarının son 10 sıradaki takımlardan daha yüksek olduğu sonucuna ulaşılmıştır (Araya ve Larkin, 2013). Türkiye Süper Liginde 20162017 sezonunda ilk 9 ve son 9 sıradaki takımların bazı performans parametrelerinin karşılaştırımasının yapıldığı bir başka çalışmada, ilk 9 sıradaki takımların attıkları gol, olumlu şut, hücum bölgesine atılan top ortalamalarının daha yüksek olduğu sonucuna ulaşılmıştır (Gürkan ve Gümüşdağ, 2018). Yine 2010 Dünya kupasında müsabakalardan galip gelen ve mağlup ayrılan takımların karşılaştırılmasının yapıldığı bir başka çalışmada, müsabakalardan galip gelen takımların gol, şut ve hedefi bulan şut ortalamalarının daha yüksek olduğu sonucuna ulaşılmıştır (Bordonau ve ark., 2013). Tüm bunlardan yola çıkarak, bu çalışma 2018 dünya kupasında maçlardan galip ve mağlup ayrılan takımların bazı performans parametrelerini karşılaştırmak amacıyla yapılmıştır.

\section{Yöntem}

\section{Çalışmanın Amacı}

Bu çalışma 2018 Dünya kupasında müsabakalardan galip gelen ve mağlup ayrılan takımların bazı performans parametrelerini karşılaştırmak amacıyla yapılmıştır. 


\section{Evren ve Örneklem}

Turnuvaya 32 takım katılmış ve turnuvada toplam 64 maç oynanmıştır. Beraberlikle biten maçlar başarı-başarısızlık durumunun tespit edilmesine bir katkısının olmayacağı düşünüldüğü için değerlendirmeye alınmamış olup, 90 dakikası galibiyetle ve mağlubiyetle sonuçlanan toplam 50 müsabakanın analizi yapılmıştır. Yine grup maçlarından sonra 90 dakikası beraberlikle sonuçlanıp uzatmalara ve penaltılara giden maçlar da çalışmaya dahil edilmemiştir.

\section{İstatistiksel Analiz}

Maçların istatistiksel verileri FífA'nın (Uluslararası Futbol Federasyonları Birliği) resmi web sayfasından elde edilmiştir. Elde edilen verilerin istatistiksel analizi için SPSS 22 paket programından yararlanılmıştır. Verilerin normal dağılım gösterip göstermediğini tespit etmek için Shapiro Wilk testi uygulanmış ve verilerin normal dağııma uygun olduğu gözlemlenmiştir. Bunun sonucunda da bağımsız gruplarda parametrik testlerden İndependent Samples $t$ testi uygulanmıştır. Veriler ortalama, standart sapma olarak verilmiş ve $p<0.05$ istatistiksel olarak anlamlı kabul edilmiştir.

\section{Analiz Edilen Parametreler}

-Atılan Gol

- Korner

- Ofsayt

- Top Kazanma

- Faul

- Sarı Kart
- Kat Edilen Mesafe

- Şut

- Hedefi Bulan Şut

- Pas

- Olumlu Pas

- Topa Sahip Olma.

\section{Bulgular}

Bu çalışma 2018 dünya kupasında müsabakaları kazanan ve kaybeden takımların bazı performans parametrelerini karşılaştırmak amacıyla yapılmıştır. 
Tablo 1: Müsabakalardan galibiyet ve Mağlubiyetle Ayrılan takımların Gol, Pas ve Şut, Korner ve Faul Parametreleri

\begin{tabular}{|c|c|c|c|c|c|}
\hline & & $\mathbf{N}$ & Ortalama & Standart Sapma & $\mathbf{p}$ \\
\hline \multirow{2}{*}{ Atılan gol } & Kazanan & 50 & 2.12 & 1.14 & \multirow{2}{*}{$0.000^{*}$} \\
\hline & Kaybeden & 50 & 0.48 & 0.71 & \\
\hline \multirow{2}{*}{ Toplam pas } & Kazanan & 50 & 460.72 & 137.24 & \multirow{2}{*}{0.331} \\
\hline & Kaybeden & 50 & 435.26 & 122.74 & \\
\hline \multirow{2}{*}{ Olumlu pas } & Kazanan & 50 & 389.78 & 135.46 & \multirow{2}{*}{0.263} \\
\hline & Kaybeden & 50 & 361.12 & 118.65 & \\
\hline \multirow{2}{*}{ Şut } & Kazanan & 50 & 13.22 & 4.61 & \multirow{2}{*}{0.104} \\
\hline & Kaybeden & 50 & 11.56 & 5.47 & \\
\hline \multirow{2}{*}{ Hedefi bulan şut } & Kazanan & 50 & 4.60 & 2.24 & \multirow{2}{*}{$0.001^{*}$} \\
\hline & Kaybeden & 50 & 3.12 & 2.07 & \\
\hline \multirow{2}{*}{ Faul } & Kazanan & 50 & 13.12 & 4.40 & \multirow{2}{*}{0.210} \\
\hline & Kaybeden & 50 & 14.20 & 4.15 & \\
\hline \multirow{2}{*}{ Korner } & Kazanan & 50 & 4.94 & 2.30 & \multirow{2}{*}{0.404} \\
\hline & Kaybeden & 50 & 4.52 & 2.70 & \\
\hline
\end{tabular}

İki grup arasında atılan gol ve hedefi bulan şut açısından istatistiksel olarak anlamlı bir farklılık gözlemlenmiştir $(p<0.05)$. Müsabakaları kazanan takımların gol ve hedefi bulan şut ortalamalarının daha yüksek olduğu sonucuna ulaşıımışıı. İki grup arasında toplam pas, şut, faul ve korner parametreleri açısından istatistiksel olarak anlamlı bir farklıık tespit edilememiştir ( $p>0.05)$.

Tablo 2: Müsabakalardan galibiyet ve Mağlubiyetle Ayrılan takımların Topa Sahip Olma, Kat Edilen Mesafe, Top Kazanma, Ofsayt ve Sarı Kart Parametreleri

\begin{tabular}{|c|c|c|c|c|c|}
\hline & & $\mathbf{N}$ & Ortalama & Standart Sapma & $p$ \\
\hline \multirow{2}{*}{$\begin{array}{l}\text { Topa sahip olma } \\
(\%)\end{array}$} & Kazanan & 50 & 51.06 & 9.63 & \multirow{2}{*}{0.274} \\
\hline & Kaybeden & 50 & 48.94 & 9.63 & \\
\hline \multirow{2}{*}{$\begin{array}{l}\text { Kat edilen } \\
\text { mesafe (km.) }\end{array}$} & Kazanan & 50 & 104.38 & 5.20 & \multirow{2}{*}{0.709} \\
\hline & Kaybeden & 50 & 103.96 & 5.98 & \\
\hline \multirow{2}{*}{ Top kazanma } & Kazanan & 50 & 9.68 & 5.12 & \multirow{2}{*}{0.086} \\
\hline & Kaybeden & 50 & 11.34 & 4.41 & \\
\hline \multirow{2}{*}{ Ofsayt } & Kazanan & 50 & 1.34 & 1.29 & \multirow{2}{*}{0.633} \\
\hline & Kaybeden & 50 & 1.46 & 1.21 & \\
\hline \multirow{2}{*}{ Sarı kart } & Kazanan & 50 & 1.40 & 1.09 & \multirow{2}{*}{$0.023^{*}$} \\
\hline & Kaybeden & 50 & 1.94 & 1.25 & \\
\hline
\end{tabular}


İki grup arasında sarı kart değişkeni açısından istatistiksel olarak anlamlı bir farklılık tespit edilmiş $(p<0.05)$ ve müsabakaları kaybeden takımların maç başı sarı kart ortalamalarının daha yüksek olduğu gözlemlenmiştir. İki grup arasında topa sahip olma, olumlu pas, kat edilen mesafe, top kazanma ve ofsayt parametreleri açısından istatistiksel olarak anlamlı bir farklılık bulunamamıştır ( $p>0.05)$.

\section{Tartışma ve Sonuç}

Bu çalışma, 2018 Dünya kupasında müsabakalardan galip gelen ve mağlup ayrılan takımları bazı performans parametreleri açısından karşılaştırmak amacıyla yapılmıştır. Müsabakalardan galip olarak ayrılan takımların maç başı atılan gol ortalamaları, hedefi bulan şut ortalamaları, sarı kart ortalamaları mağlup olan takımlardan daha yüksektir ve iki grup arasında istatistiksel olarak anlamlı bir farklılık tespit edilmiştir $(p<0.05)$. Literatür incelendiğinde elde edilen sonuçların mevcut bu çalışma ile benzerlik taşıdığı gözlemlenmiştir.

2014 Dünya Kupası Şampiyonu Almanya milli takımının analizinin yapıldığı bir çalışmada, Alman takımının 2.57 gol ortalaması ile oynadığı ve müsabakaların ilk yarısında kalesinde hiç gol görmediği gözlemlenmiştir (Göral, 2015). 2002, 2006 ve 2010 Dünya kupalarında, müsabakaları kazanan ve kaybeden takımların karşılaştırımasının yapıldığı bir çalışmada, müsabakaları kazanan takımların gol ortalamalarının 2.2, kaybeden takımları da 0.4 olduğu sonucuna ulaşılmıştır. Yine aynı çalışmada maçları kazanan takımların toplam şut ortalamalarının 14.2, maçları kaybeden takımların 10.7 olduğu, maçları kazanan takımların hedefi bulan şut ortalamalarının 7.1, kaybeden takımların 6.7 olduğu, maçları kazanan takımların sarı kart ortalamalarının 2.0, kaybeden takımların da 2.1 olduğu sonucuna ulaşılmıştır (Castellano ve ark., 2012). 2012-2013 Spor Toto Süper Lig takımlarının sezon sonu sıralamasına etki eden faktörlerin incelendiği bir çalışmada ligin ilk sıralarındaki takımların şut sayılarının, ligin son sıralarındaki takımların şut sayılarından daha fazla olduğu sonucuna ulaşılmıştır (Bostancı ve ark., 2017). 2012 Avrupa Futbol Şampiyonasının analizinin yapıldığı bir çalışmada, müsabakaları kazanan takımların gol ortalamalarının 2.17, kaybeden takımların 0.58 olduğu, maçları kazanan takımların şut ortalamalarının 5.75, kaybeden takımların ise 3.38 olduğu sonucuna ulaşılmıştır (Sgro ve ark., 2015). Yine 2014 FiFA Dünya kupasında kaleye daha fazla şut çekmenin maçları kazanmaya etkisinin \%13 olduğu, kaleye isabet eden şut sayısının fazla olmasının da \%48 oranında maçları kazanmaya etki ettiği 
gözlemlenmiştir (Liu ve ark., 2015). 2012-2017 sezonlarında Çin Süper Liginde yapılan bir başka çalışmada, müsabakaları kazanan takımların şut ve hedefi bulan şut ortalamalarının, kaybeden takımlardan daha yüksek olduğu sonucuna ulaşılmıştır (Zhou ve ark., 2018).

Yapılan mevcut çalışmada maçları kazanan takımlar ile kaybeden takımlar arasında kat edilen mesafeler açısından istatistiksel olarak anlamlı bir farklılık tespit edilememiştir $(p<0.05)$. Literatürü incelendiğinde elde edilen sonuçların mevcut bu çalışma ile benzer nitelikte olduğu gözlemlenmiştir.

İtalya seri A Liginde ilk 5 sırayı oluşturan takımlar (1-5) ile son 5 sırayı oluşturan takımların (16-20) karşılaştırmasını içeren bir çalışmada; son 5 sıradaki takımların toplam kat ettikleri mesafenin, ilk 5 sıradaki takımların kat ettikleri mesafeden daha fazla olduğu (Rampininia ve ark., 2009), 2014 sezonunda Çin Süper Liginde oynanan müsabakalarda ilk 4 sırayı oluşturan takımların (1-4) toplam kat ettikleri mesafenin, son 4 sırayı oluşturan takımlardan daha düşük düzeyde olduğu sonucuna ulaşılmıştır (Yang ve ark., 2018). 2012-2013 sezonunda Almanya Bundesliga Liginde 306 maç üzerinde yapılan bir başka araştırmada, maç koşu performansının müsabakaları kazanmak için tek başına geçerli bir yöntem olmadığı sonucuna ulaşılmışıı (Hoppe ve ark., 2015). Yine İngiltere Premier Lig, İngiltere Championship ve İngiltere Lig 1'in fiziksel performans parametrelerinin karşılaştııımasının yapıldığı bir başka çalışmada, Lig 1 deki takımların Premier lig ve Championship'teki takımlara göre daha fazla mesafe kat ettikleri, Championship'teki takımların da Premier ligdeki takımlara göre daha fazla mesafe kat ettikleri gözlemlenmiştir. Bu 3 grupta en az mesafe kat eden lig bu guruplar içerisinde en yüksek seviyeye sahip olan İngiltere Premier ligidir (Bradley ve ark., 2013). 2014 FiFA Dünya kupasında maçları kazanan takımlar ile kaybeden takımların fiziksel performans parametrelerinin (toplam kat edilen mesafe, düşük, orta ve yüksek şiddette yapılan koşular) birbirine yakın olduğu ve istatistiksel olarak anlamlı bir farklılık olmadığı sonucuna ulaşıımıştır (Rumpf ve ark., 2017).

Elde edilen bu sonuçlar; toplam kat edilen mesafe kavramının müsabakaları kazanmak için tek başına geçerli bir ölçüt olmadığı, kat edilen mesafelerin yoğunluklarının ve topla yapılan koşuların daha da önemli olabileceği sonucuna götürmektedir.

Mevcut çalışmada müsabakalardan galip gelen takımlarla, mağlup olan takımlar arasında toplam pas, olumlu pas, faul, korner, top kazanma, ofsayt 
ortalamaları ve topa sahip olma yüzdesi açısından istatistiksel olarak anlamlı bir farklılık tespit edilememiştir. Literatürdeki çalışmalarda mevcut çalışmayı destekler niteliktedir. 2016 Avrupa şampiyonası üzerine yapılan bir araştırmada, müsabakaları kazanan takımlar ile kaybeden takımlar arasında toplam pas, olumlu pas, faul, korner ortalamaları ve topa sahip olma yüzdeleri açısından istatistiksel olarak anlamlı bir farklılık bulunamamıştır. Yapılan bu çalışmada, müsabakaları kazanan takımların maç başı toplam pas ortalaması 436,46 iken, maçları kaybeden takımların 428,31 olduğu, maçları kazanan takımların olumlu pas ortalamalarının 369,31, maçları kaybeden takımların ise 358,11 olduğu tespit edilmiştir. Yine müsabakaları kazanan takımların faul ortalamalarının 12,23, kaybeden takımların 12,11 olduğu, müsabakaları kazanan takımların korner ortalamalarının 5,54, kaybeden takımların ise 4,60 olduğu, müsabakaları kazanan takımların topa sahip olma yüzdelerinin 50,66 olduğu, kaybeden takımların da 49,34 olduğu tespit edilmiştir (Gürkan ve Müniroğlu, 2018).

2002 Dünya Kupasında finale kalma başarısı gösteren Almanya ve Brezilya takımlarının analizinin yapıldığı bir çalışmada, müsabakalardan galibiyetle ayrılan takımların (Almanya ve Brezilya) maç başı toplam pas ortalamalarının 355,16, müsabakalardan mağlubiyetle ayrılan takımların toplam pas ortalamalarının ise (Almanya ve Brezilyanın rakipleri) 387,58 olduğu gözlemlenmiştir. Yine maçları kazanan takımların maç başı olumlu pas ortalamalarının 292,75, kaybeden takımların ise 314,67 olduğu tespit edilmiştir (Szwarc, 2004).

FIFA 2006 Dünya Kupasında Çeyrek Final, Yarı Final ve Final Oynayan takımların analizinin yapıldığı bir başka çalışmada, maçları kazanan takımlar ile kaybeden takımların topa sahip olma yüzdelerinin birbirine benzer olduğu sonucuna ulaşılmıştır (Arıkan, 2009). 2008-2009 sezonunda İspanya Liginde yapılan bir araştırmada, müsabakalardan galip gelen takımların korner ortalamalarının 5.2, berabere kalan takımların 5.5, mağlup olan takımların da 5.3 olduğu ve sonuçların birbirine çok yakın olduğu sonucuna ulaşılmıştır (Penas ve ark., 2010). Yine 2012 Avrupa Futbol Şampiyonası üzerine yapılan bir çalışmada maçları kazanan takımlar ile kaybeden takımların korner ortalamalarının birbirine çok yakın olduğunu sonucuna ulaşılmıştır (Sgro ve ark., 2015).

Sonuç olarak, müsabakaları kazanan takımların hedefi bulan şut ortalamalarının istatistiksel olarak anlamlı olduğu ve gol atmak için kaleye şut çekmenin çok önemli olduğu söylenebilir. Kaleye fazla şut atmanın, olumlu şut 
sayısını ve gol oranını da artıracağı söylenebilir. Bu nedenlerden dolayı da müsabakalardan galip gelen takımların daha fazla kaleye şut attıkları gözlemlenmiştir. Tüm bunlara ilaveten toplam pas sayılarının, topa sahip olma yüzdelerinin ve toplam kat edilen mesafe kavramının maçları kazanmak için bir ölçü, kriter olmadığı sonucuna ulaşılmıştır. Takımların pasları daha çok hangi bölgede yaptıklarının, topa daha çok hangi alanda sahip olduklarının ve maç içerisindeki adam eksiltici penetrasyon parametresinin daha önemli olduğu söylenebilir. Yine kat edilen mesafelerinin maçı kazanmak için tek başına bir anlam ifade etmediğini, takımların topla yapılan koşuların, yüksek şiddetli ve sprint ile yapılan koşuların da incelenmesi gerektiği söylenebilir. Günümüz modern futbolunda takımlar artık en kısa sürede rakip kalede pozisyonu sonuçlandırmaya yönelik oyun anlayışını tercih etmektedirler. Bunun içinde topla çok fazla pas yapmadan direkt topu 3. bölgeye taşıyarak rakip alanda pozisyonu sonuçlandıracak parametrelerin daha önemli olduğunu söylenebilir.

\section{Kaynaklar}

Akgeyik, T. (2018). Futbolda başarıyı etkileyen faktörler, (Türkiye süper lig takımları üzerine ampirik bir araştırma). HAK-iş Uluslararası Emek ve Toplum Dergisi. 7(18), 396-413.

Araya, J.A., Larkin, P. (2013). Key performance variables between the top 10 and bottom 10 teams in the English Premier League 2012/13 season. Human Movement, Health and Coach Education (HMHCE). 2, 17-29.

Arıkan, İ.N. (2009). FIFA 2006 dünya kupasında çeyrek final, yarı final ve final oynayan futbol takımlarının hücum organizasyonlarının incelenmesi ve maç sonuçlarına etkileri. Ege Üniversitesi Sağlık Bilimleri Enstitüsü, Hareket ve Antrenman Bilimi Anabilim Dalı. Yüksek Lisans Tezi.

Bakır, İ. (2007). Türkiye Süper Ligi'nde mücadele eden bir futbol takımının iç saha ve dış sahalarda yaptığı maçların analiz sonuçlarının karşılaştırılması. Ankara Üniversitesi, Sağlık Bilimleri Enstitüsü, Beden Eğitimi ve Spor Anabilim Dalı, Yüksek Lisans Tezi, Ankara.

Bordonau, D.L.J., Monforte, D.C., Guzman, F.J., Villanueva, M.A. (2013). Offensive and defensive team performance: relation to successful and unsuccessful participation in the 2010 Soccer World Cup. Journal of Human Sport \& Exercıse. 8(4),894-904. 
Bostancı, Ö., Ünver, Ş., Kabadayı, M., Şebin, K., İmamoğlu, M. (2017). 2012-2013 spor toto süper lig takımlarının sezon sonu sıralamasına etki eden faktörlerin incelenmesi. Atatürk Üniversitesi Beden Eğitimi ve Spor Bilimleri Dergisi. 19(2),78-88.

Bradley, P.S., Carling, C., Diaz, A.G., Hood, P. Barnes, C., Ade, J., Boddy, M., Krustrup, P., Mohr. M. (2013). Match performance and physical capacityof players in the top three competitive standards of English Professional soccer. Human Movement Science. 32(4),808-821.

Carling, C., Bloomfield, J., Nelsen, L., Reilly, T. (2008). The role of motion analysis in elite soccer. Sports Med. 38(10),839-862.

Carling, C., Williams, A.M., Reilly, T.(2005). Handbook of soccer match analysis. London: Routledge.

Castellano, J., Casamichana, D., Lago, C. (2012). The use of match statistics that discriminate between successful and unsuccessful soccer teams. Journal of Human Kinetics. 31,139-147.

Franks, I.M., Hughes, M. (2016): Successful coachıng through match analysıs. Meyer and Meyer Sport. 1nd Ed.

Göral, K. (2015). Son şampiyon Alman milli takımının 2014 fıfa dünya kupası performansının analizi. Journal of Human Sciences. 12(1), 1107-1117.

Gürkan, O., Gümüşdağ, H. (2018). 2016-2017 Türkiye süper ligini ilk 9 ve son 9 sırada tamamlayan takımların bazı performans parametrelerinin karşılaşı̧ımalı analizi. Journal of International Multidisciplinary Academic Researches. 5(1),1421.

Gürkan, O., Müniroğlu, S. (2018). 2016 Avrupa futbol şampiyonasındaki müsabakaların teknik-taktik açıdan analizi. Spormetre. 16(3),101-108.

Hoppe, M.W., Slomka, M., Baumgart, C., Weber, H., Freiwald, J. (2015). Match running performance and success across a season in German bundesliga soccer teams. Int J Sports Med. 36(7),563-566.

Hughes, M., Franks, I. (2005). Analysis of passing sequences, shots and goals in soccer. J Sport Sci. 23(5),509-514.

Hughes, M. (2003). Notational analysis. Reilly, T., Williams, A.M. (Ed.). Match analysis. Science and Football (ss.245-265). 
İnan. T. (2018). Analyzing the home-field advantage in major european football leagues. Internatıonal Journal of Environmental \& Scıence Educatıon. 13(2), 113-124.

Lıu, H., Gomez, M.A., Penas, C.L., Sampaı, J. (2015). Match statistics related to winning in the group stage of 2014 brazil fifa world cup. Journal of Sports Sciences. 33(12), 1205- 1213.

Müniroğlu, S. (2009): Futbolda müsabaka analizi ve gözlemin önemi. 3. ulusal futbol bilim kongresi. S:17.

Müniroğlu, S., Deliceoğlu, G. (2008). Futbolda müsabaka analizi ve gözlem teknikleri. Ankara Üniversitesi Basımevi. 1. Baskı. Ankara.

Peñas, L.C., Ballesteros, L.J., Rey, E. (2011). Differences in performance indicators between winning and losing teams in the UEFA Champions League. Journal of Human Kinetics. 27(1), 135-146.

Penas, L.C., Ballesteros, L.J., Dellal, A., Gomez, M. (2010). Game-related statistics that discriminated winning, drawing and losing teams from the spanish soccer league. J Sports Sci Med. 9(2),288-293.

Rampininia, E., Franco, M., Impellizzeri, A.B., Carlo Castagnac, C., Couttsd, A.J., Wisløff, U. (2009). Technical performance during soccer matches ofthe Italian SerieA league: Effect of fatigue and competitive level. Journal of Science and Medicine in Sport. 12(1), 227-233

Rumpf, C.M., Silva,R.J., Maxime, H., Farooq, A., Nassis, G. (2017). Technical and physical analysis of the 2014 FIFA World Cup Brazil: Winners vs. Losers. The Journal of sports medicine and physical fitness. 57(10), 1-15.

Sgro, F., Barresı, M., Lıpoma, M. (2015). The analysis of discriminant factors related to team match performances in the 2012 european football championship. Journal of Physical Education and Sport. 15(3),460-465.

Szwarc, A. (2004). Effectiveness of brazilian and german teams and the teams defeated by them during the 17th fifa world cup. Kinesiology. 1,83-89.

Yang, G., Leicht, A.S., Lago, C., Gomez, M.A. (2018). Key team physical and technical performance indicators indicative of team quality in the soccer Chinese Super League. Researchın Sports Medıcıne. 26(1),1-10.

Zhou, C., Zhang, S., Calvo, L.A., Cui, Y. (2018). Chinese soccer association super league, 2012-2017: key performance indicators in balance games. Internatıonal Journal of Performance Analysıs in Sport. 18(4),645-656. 